\title{
COTIDIANO ESCOLAR E COMPLEXIDADE: VIVENDO ENTRE ORDENAÇÕES PROVISÓRIAS E FLUTUAÇÕES CAÓTICAS
}

\author{
REIS, Maria Cláudia ${ }^{1}$
}

A vida, em contrapartida, é troca contínua, com intercomunicações e reações incessantes. A vida é desequilíbrio, conflitos perpétuos e, a este título, contradições.

Edgar Morin

\begin{abstract}
RESUMO
O presente artigo é parte de um estudo de investigação dos processos que envolveram a elaboração de uma proposta político-pedagógica coletiva no cotidiano de uma escola pública de horário integral, em Niterói. A partir do pensamento de alguns autores da chamada ciência da complexidade ou teoria do caos, as ideias apresentadas neste texto representam um movimento de tentar compreender episódios, aparentemente inesperados, tecidos no interior do espaço-tempo da escola, fruto da interação entre os sujeitos que o constitui. São situações que exigem um exercício de reflexão complexo, onde é necessário "baixar as armas" da objetividade e da linearidade deterministas, em busca de uma lógica de compreensão aberta e diferenciada. Faz-se necessário, então, perceber o cotidiano escolar como o lugar da complexidade e da imprevisibilidade, onde os processos que o envolvem nos colocam diante da incapacidade de afirmar, certificar e absolutizar, já que ficamos expostos ao desafio de pensar sobre o inacabado e o provisório como características da sua dinâmica.
\end{abstract}

PaLAVRAS-ChaVe: Cotidiano Escolar - Interação - Fazer Pedagógico - Complexidade.

\begin{abstract}
This article is part of an ongoing investigation about the processes related to the elaboration of a collective political-pedagogical proposal by the participants of a full time public school, in the city of Niteroi, Brazil. Based on some authors from the so called science of complexity or chaos theory, the ideas presented in this text are an attempt to understand apparently unexpected events resulted from the interaction which occurred within the space/time duality in the school. It was perceived that those situations demand a complex exercise of reflection, where it is necessary to let go of objectivity and of the linear deterministic viewpoint, in search of a differen-

\footnotetext{
${ }^{1}$ Professora Assistente UERJ, lotada no Instituto de Aplicação Fernando Rodrigues da Silveira (CAp). Mestre em Edu-
} cação pela UFF, doutoranda em Ciências Sociais pela PUC-Rio. E-mail: mcoliveirareis@gmail.com
\end{abstract}




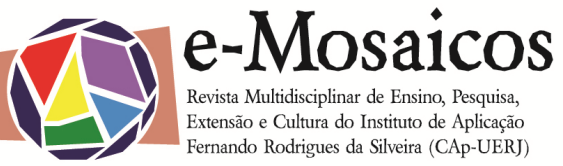

tiated logic to understanding., So, it is paramount to view daily school as place of complexity and unpredictability, where processes make us face the incapability to affirm, certify or to make anything absolute, since we are dealing with the provisory and the unfinished, which are essential characteristics of its dynamics.

KeYWORDS: Daily School - Interaction - Pedagogical Practice - Complexity.

\section{CONSIDERAÇÕES INICIAIS: O ESPAÇO-TEMPO ORIGINÁRIO DAS IDEIAS}

O presente artigo é parte de uma pesquisa realizada, entre os anos de 2001 e 2004, em uma escola pública de horário integral, no bairro de São Domingos, em Niterói ${ }^{2}$. O estudo teve como objetivo investigar o trabalho coletivo no cotidiano dessa escola, buscando compreender e identificar alguns dos principais desafios que se apresentam à produção e à execução de um projeto político-pedagógico.

Entre os elementos investigados, a pesquisa empreendeu uma reflexão sobre os conflitos relacionais e as disputas de poder presentes nas relações que constituíam o espaço-tempo escolar, reconhecendo que estes fatores representavam grandes obstáculos à organização coletiva do trabalho, dificultando uma maior integração dos saberes/fazeres dos sujeitos envolvidos na formulação e na realização das ações pedagógicas. Dessa forma, para pensar e discutir tal problemática, foi necessário recorrer aos fundamentos de uma nova ciência que concebe o caos, o antagonismo e a contradição como fontes potenciais no movimento de

\footnotetext{
2 As ideias deste artigo estão presentes na dissertação de mestrado, intitulada $O$ fazer pedagógico como um fazer coletivo: Desafios do cotidiano escolar na construção de uma proposta político-pedagógica, que apresentei ao Programa de Pós-Graduação em Educação da UFF, no ano de 2004, sob a orientação da Professora Doutora Maria Teresa Esteban. A pesquisa consistiu na investigação dos processos que envolveram a elaboração do projeto político-pedagógico do CIEP Geraldo Reis, atual Colégio Universitário da UFF.
}

produção da ordem, ou seja, como forças auto-organizativas da realidade cotidiana. Portanto, Jacques Atalli e Edgar Morin foram interlocutores referenciais, que procurei entrelaçar aos pensamentos de Humberto Maturana, Leonardo Boff e Hannah Arendt.

\section{EXPERIÊNCIA, COMPLEXIDADE E REFLEXÃO}

A vivência e a pesquisa no/do/com o cotidiano escolar me levaram a compreender que este é o lugar da complexidade e da imprevisibilidade, onde os processos que o envolvem nos colocam diante da incapacidade de afirmar, certificar e absolutizar, já que ficamos expostos ao desafio de pensar sobre 0 inacabado e o provisório que 0 constituem. No seu interior, diferentes projetos tecem-se numa rede de antagonismos, contradições e conflitos que incorporam as ações que ora coletivizam-se, ora fragmentam-se, constituindo a dimensão dialógica desse micro-espaço, onde se abrigam também os princípios da ordem e da organização, ainda que provisórias.

É nessa perspectiva que a tentativa de compreender episódios, aparentemente inesperados, que são tecidos no interior do espaço-tempo da escola, levou-me a um exercício de reflexão complexo que procurou baixar as armas da objetividade e da linearidade deterministas.

A experiência de anos de docência e de pesquisa em diferentes cotidianos escolares me fez entender, assim como CAPRA (1993), que uma compreensão da vida, em 
todos os níveis, se dá através da interconexão dos contrários. Visto que o cotidiano escolar se apresenta como um lócus do agir social de latente complexidade, não há como compreendê-lo a partir da exclusão de seus antagonismos; parafraseando BHABHA (1998): não pode ser só isto ou aquilo, $e$ sim isto e aquilo, e as múltiplas possibilidades que vão surgindo no contexto de negociações permanentes desse enredado processo, contínuo, de interações humanas.

Essa minha postura forjou-se então na necessidade de encontrar um instrumento que me levasse à compreensão dos movimentos que acontecem no/do/com cotidiano da escola e que me permitisse pensar as ações que se processam no seu interior, a partir de uma percepção da sua complexidade. Fiz então a opção por tentar realizar o paradoxo de entrelaçar contradições e antagonismos, buscando dar-lhes um sentido de complementaridade.

Nesse percurso de ação-reflexãoação, buscando compreender os processos que se dão nas relações entre os sujeitos que realizam o trabalho na escola, encontrei, na teoria da ordem pelo ruído (ATTALI, 1993), uma ideia que possibilita esse movimento de compreensão: "(...) quando um ruído agride uma forma, ele se introduz como um "parasita" que intercepta a comunicação (...) e então a (...) sobrevivência do grupo depende de sua capacidade de gerir os parasitas, em canalizar aquilo que perturba, eliminar o que agride, prevenir a violência, dar um sentido ao bem e ao mal" (ATTALI, 1993, p. 173).

Como administrar os "ruídos" e dar sentido "ao bem e ao mal" que interceptam os processos comunicativos entre os sujeitos do espaço-tempo do trabalho escolar?

\section{A DIALÓGICA MORINIANA}

A ação de refletir sobre a capacidade diferenciada que os sujeitos escolares apresentam, especialmente os docentes, de eliminar as "perturbações" eminentes que surgem no trabalho pedagógico coletivo, me aproximou da ideia que Edgar Morin denomina de passagem da dialética à dialógica (SANCHÉZ, 1999). Entendendo que as ações no micro-território da escola possam ser pensadas a partir deste movimento, que não prevê a superação da contradição, antes a integra como parte de uma racionalidade aberta à complexidade que envolve as situações cotidianas, uma racionalidade que, tecida pela dúvida, aceita limites e abriga contradições (MORIN, 2002c).

Diferentemente da dialética hegeliano-marxista, que propõe a superação das contradições e antagonismos, MORIN (2002c) acredita que existe um potencial produtivo nos elementos contraditórios e antagônicos presentes no pensamento e na ação, que não devem ser superados, mas reconhecidos, pois são reveladores da existência de realidades simultâneas dentro de um mesmo sistema. A dialógica moriniana surge então da necessidade de unir os aspectos, ao mesmo tempo complementares e antagônicos, capazes de gerar um movimento próprio de organização.

Eliminar a contradição, afirmando-a meramente como tal, é encerrar a possibilidade de leituras que produzam compreensões diversificadas do funcionamento de um mesmo sistema. Quando vou me permitindo buscar a produção de uma lógica aberta na interação com as ações que se processam no/do/com cotidiano da escola, envolvendo os diferentes sujeitos que nele co-habitam, vejo-me elaborando um percurso que me reconcilia com esse espaço-tempo, sem que corrobore com o conservadorismo impregnado em muitas das ações e relações dentro dele. Desempenho, sobretudo, uma luta 
recorrente pela sobrevivência da amorosidade, sem a qual perco o sentido de estar e de agir.

A concepção de contradição em MORIN (2002c) ajuda-me a compreender o cotidiano escolar como um território que se constitui de noções antagônicas: entre o fazer e o não-fazer, entre o dinâmico e 0 inerte, entre o planejado e o aleatório, entre o democrático e o autoritário, entre a inclusão e a exclusão, entre o coletivo e o isolamento, entre o engajamento e a acomodação, entre o sucesso e o fracasso, entre a ruptura e a permanência, entre o transformador e o conservador. Enfim, essa concepção (da contradição) auxilia-me no entendimento da cultura desse espaço como uma dialógica permanente (MORIN, 2002b) que não recusa o contraditório e o antagônico, antes se lança ao enfrentamento, dialógico, de ambos, como possibilidade para se chegar ao diálogo. MORIN (2002c) me ajuda a compreender o cotidiano como um espaçotempo onde opera não apenas a ordem e a limitação, mas também como uma organização complexa, que se constitui na produção da desordem e da ordem iminentes, como um território potencializador de uma práxis onde "(...) os contrários se entredilaceram, se superam e se reformam." (MORIN, 2002, p.37).

\section{ETHOS COMO UM MODO DE SER DAS PESSOAS NOS ESPAÇOS PÚBLICO E PRIVADO}

Nas situações que envolvem os aspectos relacionais dos grupos que compõem a escola, com o alcance ou não de uma maior capacidade de diálogo frente aos conflitos que surgem na convivência, algumas falas sinalizam que há certa dificuldade dos sujeitos em perceberem os limites entre 0 pessoal e o profissional. Em alguns espaços, os confrontos que se dão em torno de al- guma tarefa considerada pelo grupo como mal desempenhada são encarados como rivalidades interpessoais.

De fato, qualquer problema que se apresenta no cotidiano escolar, como esfera comunitária, vai estar relacionado diretamente às pessoas, já que é um espaço, por excelência, de interações e relações sociais. É possível perceber que em muitos momentos não conseguimos fazer a distinção entre uma esfera de vida pública e uma esfera de vida privada, encaminhando nossas ações como se estivéssemos organizando um grande cômodo doméstico, como se a escola fosse um grande lar. Tornou-se cultural a afirmação - que circula no imaginário de docentes, funcionários/as e fortemente no imaginário dos estudantes - de que "a escola é nossa segunda casa" e "a professora é nossa segunda mãe"; tudo está em família, todas e todos são tias e tios.

Segundo BOFF (2003), esse sentimento de não-distinção entre o público e o privado foi motivo de reflexão para alguns filósofos da Antiguidade. Ao refletir sobre a ética, BOFF (2003) recorre ao pensamento de Heráclito (500 a.C), filósofo présocrático, identificando que a humanidade se relaciona com o espaço planetário como se fosse um grande lar. Esta formulação, para BOFF (2003), esconde a chave para toda uma construção ética que estaria ligada a uma concepção de morada:
(...)ethos (no grego) não é primeira- mente ética, mas a morada humana. Ethos/morada não é constituída sim- plesmente pelas quatro paredes e o te- to. É o conjunto das relações que o ser humano estabelece com o meio natu- ral, separando um pedaço dele para que seja sua morada, com os que habi- tam na morada... Morada é..., portan- to, um modo de ser das pessoas e das coisas. (BOFF, 2003, p.13) 


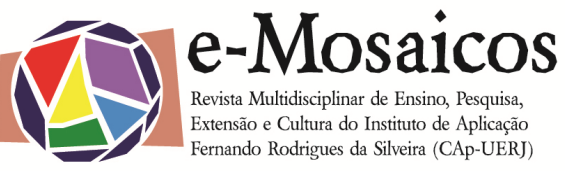

A morada doméstica pode ser considerada o lócus primário das interações humanas. Se o significado original da palavra $e$ thos refere-se à morada, ampla, no sentido planetário, como um modo de ser das pessoas, penso então que não há como divisar rigidamente o nosso modo de ser privado do nosso modo de ser público. No que se refere ao ethos/morada, como um modo de ser das pessoas - portanto, também como um modo de estar entre as pessoas - os princípios relacionais fundamentais que regem as vidas privada e pública não apresentam diferenças. $O$ respeito, a honestidade, o cuidado, o companheirismo, a amizade, a solidariedade, a justiça etc. são princípios que estariam relacionados a uma ética de ser e de estar entre as pessoas, tanto na esfera da vida pública, quanto na esfera da vida privada.

Sobre essa questão, ARENDT (1993) também me possibilita desdobrar algumas reflexões, quando aborda a nossa dificuldade de uma compreensão entre as esferas pública e privada: entre a esfera da polis e a esfera da família. Esta divisão, que teve sua origem desde o surgimento das antigas cidades-estado, segundo a autora, era a base axiomática de todo o antigo pensamento político. Neste sentido, é preciso esclarecer que os gregos diferenciavam o ser social do ser político. O primeiro estaria ligado a uma diferenciação pouco distinta para nós que operamos com uma compreensão moderna desses termos. No mundo moderno, como identifica ARENDT (1993), as esferas social e política estão entrelaçadas uma à outra, não havendo mais o abismo dos antigos entre o privado e o público. A nossa compreensão dessa demarcação não é inteiramente divisada, como equacionava o antigo pensamento político. Tendemos assim a uma visão familiar na concepção de organi- zação política da sociedade: "(...) vemos o corpo de povos e comunidades políticas como uma família cujos negócios diários devem ser atendidos por uma administração doméstica nacional e gigantesca (...) uma espécie de administração doméstica coletiva." (ARENDT, 1993, p.38)

\section{RAZÃO EMOCIONAL}

Com o auxílio desse pensamento de ARENDT (1993), que entrelaço a algumas ideias de MATURANA (1997), sou levada a perceber que as esferas social e política como esferas de interações humanas - são condicionadas e retroalimentadas pelos afetos. Aliás, compreendo a própria razão, que permeia as interações, como uma dimensão também permeada de afeto; ou seja, uma "razão afetiva" que vai na direção do que MATURANA (1997) afirma: '(...) todo sistema racional tem um fundamento emocional" (1997, p.171). As emoções são, então, a priori da razão e abrem campos específicos de ações. Este autor ressalta o aspecto primordial das emoções na existência humana, afirmando que esta se realiza "(...) na linguagem e no racional partindo do emocional" (1997, p.170).

As emoções, segundo MATURANA (1997), são "(...) disposições corporais que especificam domínios de ações, e que as diferentes emoções se distinguem precisamente porque especificam domínios de ações distintos" (1997, p.170). Porém, no uso da nossa "razão-ação emocional", o que percebo muitas vezes no cotidiano do trabaIho na escola é que tendemos a revelar algumas contradições que se originam no processo que exige de nós uma ação específica de conciliação entre o nosso mundo privado/familiar com o nosso mundo profissional. Será que é possível a separação emocional/afetiva entre uma esfera e outra? Ou melhor, será que é possível a produção de emoções/ações particulares para cada 


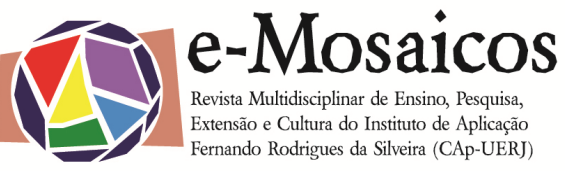

uma dessas esferas?

Estes questionamentos me levaram a refletir sobre a opinião que os sujeitos escolares, docentes e funcionárias\os, têm sobre os embates e os confrontos emocionais que por vezes se estabelecem nos espaços de reuniões para planejamento e outras atividades. Consegui então encontrar em MORIN (2002b) um depoimento que me fornece recursos para uma reavaliação desses momentos conflituosos:

\section{(...) uma exigência, ao mesmo tempo intelectual e ética, convida-me (nem sempre com êxito) a me omitir em uma discussão e, sobretudo, em uma disputa. Enquanto cada um se autojus- tifica e condena o outro no debate, sei que, muito frequentemente, o jogo re- cíproco das críticas, seguidas de repri- mendas e de invectivas, às vezes tam- bém de insultos, vem do círculo inter- retroativo que constitui a própria dis- cussão. É mais saudável se isentar, porque a vida cotidiana de cada um es- tá tecida, segundo um processo "histé- rico" de boa-má-fé, de consciência ob- tusa de suas próprias agressões, de hi- perconsciência das agressões dos ou- tros, de deformações incessantes dos propósitos do outro. (MORINb, 2002, p.81)}

A partir dessa leitura, vou conseguindo compor um novo quadro dos momentos de encontros coletivos no cotidiano da escola, sobre o "processo "histérico" de boa-má$f e ́$ " que por vezes os constitui. Posso então me perceber num movimento de repensar a própria postura, identificando meu próprio foco de contradição interna quando, apesar de defender uma organização participativa do trabalho escolar, no fundo, alimento um desejo de anulação de algumas participações, ou melhor, de alguns participantes. Situações em que, por vezes, assumo uma razão política que enxerga apenas o diferente/antagônico como um inimigo que precisa ser combatido e vencido (MORIN, 2000b).

Conquanto acredite que o conflito político seja inevitável, seja parte de todo processo no qual estão em constante interação as ações de diferentes sujeitos que encarnam diferentes projetos, convergentes e divergentes, creio também na possibilidade, ao mesmo tempo ética e estratégica, de confrontar o "adversário", em alguns momentos, a partir de uma compreensão tolerante. No entanto, não posso deixar de identificar aqui a diferença de concepção entre os autores (Humberto Maturana e Edgar Morin), que me ajudam a pensar a questão que envolve as interações, dentro do espaço escolar e da vida social como um todo.

MATURANA (1998) fala da aceitação mútua como a única forma de legitimar a existência do outro na sua singularidade de ideias e de ações. Considera que esse é o único caminho para a construção de um modo de viver democrático, não-excludente: $A$ aceitação do outro como um legítimo outro na convivência constitui(-se) "(...) como a única convivência na qual o modo de conviver surge e se dá na aceitação, e não na negação (...) que surge na exigência de que o outro seja diferente" (MATURANA, 1998, p.83). Para esse mesmo autor, a tolerância oculta uma forma de não-aceitação legítima do outro, ou seja, ela se apresenta como uma negação postergada (MATURANA, 1998, p.50) do outro que, na divergência ideológica, é visto como um equivocado, um adversário a ser combatido; a tolerância seria então "(...) uma negação suspensa temporariamente" (MATURANA, 1998, p.93).

MORIN (2002b) parece não conceber o processo de convivência da mesma forma que MATURANA (1998). No entanto, não 
posso afirmar que sua concepção de tolerância traz subjacente o sentido de anulação postergada. Ele próprio ressalta a necessidade de se resistir a uma lógica política que só consegue discernir inimigos a serem combatidos e vencidos. A tolerância para MORIN (2000b) abriga o princípio democrático de "(...) alimentar-se de opiniões diversas e antagônicas (...)" (2000b, p.83) fazendo compreender que "(...) há uma verdade na ideia antagônica à nossa e é esta verdade que é preciso respeitar" (2000b, p.85).

Ambos, no entanto, direcionam suas ideias no sentido da produção de uma ética da inclusão. MATURANA (1998) fala de aceitação mútua e MORIN (2000b) de uma ética da compreensão. Esta pressupõe: "Compreender por que e como "eles" chegam a ideias, opiniões e crenças que julgamos absurdas ou ignóbeis (...) exige argumentar, refutar, em vez de excomungar e lançar anátemas (...) A compreensão não desculpa nem acusa" (2000b, p.91).

Para MORIN (2000b), o exercício da ética da compreensão implica em conceber a noção de indivíduo a partir da noção de personalidades potenciais, ou seja, trazemos em nós possibilidades contraditórias "(...) de genialidade e de demência, de bondade e de crueldade, de santidade ou de monstruosidade (...) que podem se desdobrar em circunstâncias excepcionais" (MORIN, 2000b, p.84). O entendimento dessa noção, segundo ele, pode nos levar a uma forma de julgar as ações, tanto nossas como as do outro, de maneira diferenciada e complexa: por um lado pode nos levar à tolerância e por outro à compreensão.

Confesso que o princípio de convivência pensado por MATURANA (1998), que se constitui a partir da aceitação do outro como um legítimo outro na convivência, apesar de admirável, apresenta-se a mim como uma difícil tarefa e um desafio a ser vivido. Pois minha tendência é sempre ter uma consciência restrita do outro, por encontrarmo-nos, eu e o outro, na maioria das vezes, sob domínios emocionais e racionais distintos, impedindo-nos de nos aceitarmos mutuamente. Portanto, e por ora, diante dos limitados recursos emocionais e racionais de que disponho, tenho tentado adotar a opção ética/estratégica de, em alguns momentos, compreender e em outros tolerar, o diferente/antagônico/divergente, como uma resposta ao desafio que me é imposto pela incerteza diante da ação. Esse é um procedimento que venho tentando assumir, nem sempre com êxito, já que a pulsão em muito encurrala a razão.

\section{O MOVIMENTO DA AUTOCRITIQUE}

Admito que o desenvolvimento da pesquisa revelou-se num exercício pródigo de autoconhecimento. Um exercício no qual tenho sido levada a integrar-me à minha observação, no esforço de compreender as questões que me constituem, a fim de exercer uma autocompreensão e uma autocorreção.

Busco um movimento de autoobservação permanente que passo a assumir como um princípio de pensamento e uma necessidade ética. Como diria MORIN (2002b), trata-se de uma autocritique, que me permite reconhecer as armadilhas da autojustificação, da hiperconsciência das agressões do outro e da deformação dos seu propósitos, e assim romper com o autoengano, "(...) numa higiene existencial que mantém (...) (minha) consciência em estado de vigília permanente" (MORIN, 2002b, p.81).

Tenho buscado compreender algumas atitudes que parecem centralizadoras e contradizem a prática democrática de alguns 
sujeitos, a partir das personalidades potenciais que cada um de nós pode desenvolver ou atualizar diante de determinados acontecimentos ou acidentes capazes de tornar louco o sábio e vice-versa; numa evocação das dimensões de sapiência e demência que constituem nosso ser, numa circular hierarquia entre razão, afetividade e pulsão (MORIN, 2002b).

A limitação da minha razão, fortemente impregnada dos determinismos de uma lógica clássica, torna estreita e opaca também a visibilidade que tenho de alguns acontecimentos que se processam no interior do espaço-tempo da escola. Assim como afirma ALVES (2002): "(...) é preciso 'notar' que também vivo e produzo conhecimentos no cotidiano, todos os dias (...) Portanto, não tenho nenhuma garantia de que não vou me iludir e de que não vou "ver" coisas e fatos inexistentes" (ALVES, 2002, p.16).

Diante desse risco ilusório, eminente, investigar a ambivalência dos acontecimentos que se dão no interior do micro-espaço escolar, inevitavelmente, leva-me a incorporar a razão de macroconceitos: "Conceitos que ponham em jogo as relações e não que isolem essências. Conceitos que abracem os contrários e não que escamoteiem a contradição" (MORIN, 2002c, p.67). É preciso incorporar conceitos e formulações que me permitam pensar/repensar os fatos sem concluí-los, já que me encontro imersa no terreno da complexidade latente, onde ver significa ver o que se sabe e o muito do que não se sabe. Portanto, é necessário estar aberta a uma análise também complexa, entrelaçada a interlocuções com os campos mais variados do conhecimento como a Filosofia, a Sociologia e alguns princípios da Física do caos e da nova Biologia.

\section{POR ORA, ORDENAÇõES PROVISÓRIAS ENTRE}

\section{FLUTUAÇÕES CAÓTICAS}

Lévy-Leblond (1993), crítico de ciência, tem uma formulação que me ajuda a compreender a incerteza que vivo diante de episódios relacionais turbulentos no cotidiano da escola, em que a identificação da causalidade e da previsibilidade apresentase rompida diante do inesperado. Esse autor afirma que "(...) certas estruturações, certas formas de ordem podem estabelecer-se de maneira espontânea em um sistema fora de equilíbrio" (LEBLON, 1993, p.167). Esse ponto de vista me assegura ampliar um pouco mais a minha capacidade de compreender os domínios de realidade do cotidiano que, sob o desprestígio da ciência, é considerado como o terreno da desordem, do ingovernável, portanto, do irracional.

Os desdobramentos de episódios que fizeram surgir novas formas de ação e organização no trabalho escolar, fizeram-me constatar um princípio defendido por ATLAN (1993), semelhante a Lévy Leblond, de que é possível a "(...) emergência de fenômenos ordenados (ainda que provisórios) a partir de turbulências ou flutuações caóticas" (ATLAN, 1993, p.15).

Para ATALLI (1993), os processos comunicativos e de sentido são fundamentais para a permanência de uma ordem que se estabelece mesmo em meio a situações caóticas: "(...) uma ordem só existe, uma forma só se mantém se é capaz de fazer circular informações que tenham um sentido para cada uma das partes" (ATALLI, 1993, p.173).

Segundo esse autor, a existência de uma determinada ordem social se dá, ainda que de forma provisória - já que se encontra na perpétua eminência de ser desordenada por "ruídos" - quando os processos de comunicação entre os sujeitos que a integram conseguem conferir uma significação 


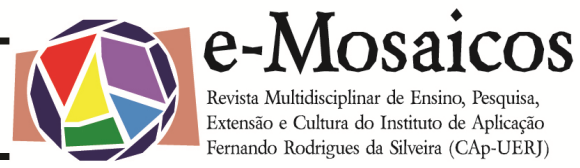

coerente com as informações que partilham entre si. De forma semelhante, CAPRA (1996) afirma a importância dos processos de comunicação em rede, geradores de laços de realimentação, que contribuem para a auto-organização permanente de uma comunidade:

Uma comunidade que mantém uma rede ativa de comunicação aprenderá com seus erros, pois as consequências de um erro se espalharão por toda a rede e retornarão para a fonte ao longo de laços de alimentação. Desse modo, a comunidade pode corrigir seus erros, regular a si mesma e organizar a si mesma. (1996: 78/ apud FERRAÇO, 2002, p.106)

Entre os desafios que se impõem à organização e à realização do fazer pedagógico coletivo na escola, está o de manter uma rede ativa de comunicação entre os sujeitos que praticam esse fazer, onde produza e faça circular informações que façam sentido para todas $\backslash o s$ as $\backslash$ os envolvidos. Porém, considerando que a complexidade e a ambivalência estão presentes nos assuntos que envolvem a esfera do próprio cotidiano escolar, onde quase tudo são oscilações: previsível/imprevisível, rotineiro/ingovernável, solidez/flutuações, calmarias/virações, céu/inferno...

Enfim, o cotidiano escolar revela-se como uma odisseia de alegrias e frustrações e pesquisá-lo requer subverter fronteiras teóricas, paradigmáticas, metodológicas e epistemológicas, aguçando os diferentes sentidos no movimento de percepção dos acontecimentos que envolvem razões e desrazões, emotivas elou intuitivas, que vão exigir do pesquisador a produção de uma investigação que "bagunce" a tradicional linearidade da pesquisa, transversalizando diferentes percursos, que possam enrique- cer e ampliar a capacidade de compreensão das histórias cotidianas que vão sendo tecidas entre flutuações caóticas e ordenações provisórias.

\section{REFERÊNCIAS BIBLIOGRÁFICAS:}

ALVES, Nilda. Decifrando o pergaminho: o cotidiano das escolas nas lógicas das redes cotidianas. In: BARBOSA, Inês e ALVES, Nilda (Orgs). Pesquisa no/do cotidiano das escolas: sobre a rede de saberes. Rio de Janeiro: DP\&A, 2002.

ARENDT, Hannah. A condição humana. Rio de Janeiro: Forense Universitária, 1993.

ATLAN, Henri. "Teórico da autorganização". In: PESSIS-PASTERNAK, Guitta (Org.). Do caos à inteligência artificial. São Paulo: UNESP, 1993.

ATTALI, Jacques. "Prospector de Horizontes". In: PESSIS-PASTERNAK, Guitta (Org.). Do caos à inteligência artificial. São Paulo: UNESP, 1993.

BHABHA, Homi. O local da cultura. Belo Horizonte: Ed. UFMG, 1998.

BOFF, Leonardo. Daimon e Ethos. Jornal do Brasil: 27 de junho de 2003.

Saber Cuidar: ética do humano - compaixão pela terra. Petrópolis, RJ:Vozes, 1999.

CAPRA, Fritjof. "O físico zen". In: PESSISPASTERNAK, Guitta (org.). Do caos à inteligência artificial. São Paulo: UNESP, 1993.

FERRAÇO, Carlos E. Ensaio de uma metodologia efêmera: ou sobre as várias maneiras de se sentir e inventar o cotidiano escolar. 
In: BARBOSA, Inês e ALVES, Nilda (Orgs).

Pesquisa no/do cotidiano das escolas: sobre a rede de saberes. Rio de Janeiro: DP\&A, 2002.

LÉVY-LEBLOND, Jean-Marc. "Crítico de Ciência" In: PESSIS-PASTERNAK, Guitta (Org.). Do caos à inteligência artificial. São Paulo: UNESP, 1993.

MATURNANA, Humberto. Emoções e linguagem na política e na educação. Belo Horizonte: Editora UFMG, 1998.

MORIN, Edgar. Meus Demônios. Rio de Janeiro: Bertrand Brasil, 2002.b

\section{Os Fundamentos Perdi-}

dos. Porto Alegre: Sulina, 2002.c

SÁNCHEZ, Ana. "A noção da dialógica e meus encontros com E. Morin". In: PENAVEGA, Alfredo e ALMEIDA, Elimar P. de (Orgs.). O Pensar complexo: Edgar Morin e a crise da modernidade. Rio de Janeiro: Garamond, 1999. 